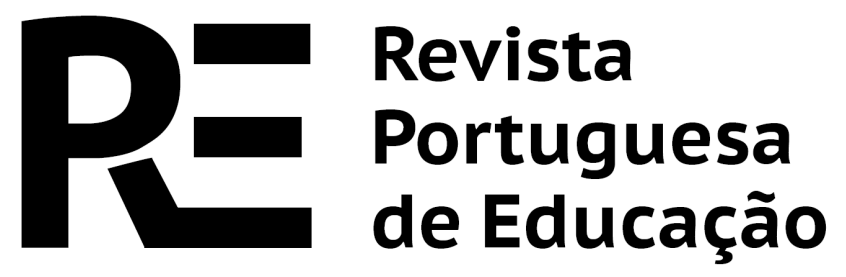

\title{
A convivência entre a aprendizagem online e presencial no processo de formação dos alunos: Um estudo de investigação-ação sobre a operacionalização da "Sala de aula invertida" no ensino secundário português
}

\author{
RESUMO
}

O Projeto de Autonomia e Flexibilidade Curricular (PAFC) desafia as dinâmicas de trabalho das escolas, através de normativos que preconizam práticas inovadoras promotoras de aprendizagens diferenciadas e competências transversais. A aprendizagem híbrida é apontada como a chave para a renovação das práticas escolares, pois possibilita aprendizagens mais dinâmicas e personalizadas. Este texto avalia uma proposta educativa de aprendizagem híbrida, a "sala de aula invertida", concebida de modo a operacionalizar os princípios do PAFC. Nesse sentido, um ciclo de investigação-ação, desenvolvido numa turma do ensino secundário, permitiu recolher dados quantitativos e qualitativos para avaliar essa operacionalização e compreender o impacto da proposta nos resultados escolares e nas perceções dos alunos. A análise dos resultados destaca na proposta a inovação, o envolvimento dos alunos e a complementaridade entre a aula online e presencial, o que proporcionou uma experiência integrada de aprendizagem suportada pelo apoio do professor. As interações em sala de aula permitiram que os alunos ampliassem os conteúdos estudados autonomamente e desenvolvessem dimensões cognitivas de ordem superior. No entanto, o processo de construção do conhecimento não pôs em evidência as competências sociais valorizadas nas dinâmicas de grupo e na aprendizagem colaborativa preconizada no PAFC.

Palavras-chave: Projeto de Autonomia e Flexibilidade Curricular; Aprendizagem híbrida;

Sala de aula invertida

\section{INTRODUÇÃO}

O relatório do Fórum Económico Mundial intitulado "Futuro do trabalho" indica que $65 \%$ das crianças que hoje estão na escola terão empregos que ainda não existem (WEF, 2018). Este facto, que resulta da profunda imersão

Teresa Ribeirinha ${ }^{i}$

CIEd-IE Universidade do Minho, Portugal

Bento Silva ${ }^{i i}$

CIEd-IE Universidade do Minho, Portugal 
tecnológica em que vivemos geradora de sinais mutáveis e imprevisíveis, alerta para a necessidade de modificar os projetos educacionais de modo a promover novas competências nos alunos.

Perante este cenário de revolução tecnológica a Comissão Europeia através do Plano Estratégico de Educação e Formação 2020, priorizou, não só, a partilha de experiências de aprendizagem que exigissem a construção de conhecimentos em processos colaborativos, mas também o desenho de estratégias com vista à aquisição de competências digitais.

Nas escolas portuguesas essas recomendações assumiram a forma de uma política de mudança curricular denominada de "Projeto de Autonomia e Flexibilidade Curricular (PAFC)". Este projeto prevê que um ensino de qualidade e sucesso passe por um currículo centrado no aluno, integrador e flexível que promova o trabalho colaborativo e a educação para a Cidadania (Despacho no 5908, de 5 de julho de 2017). Na sua base está o documento "Perfil dos Alunos à Saída da Escolaridade Obrigatória", de forte pendor humanista, articulado com um dos pilares da educação do futuro, "ensinar a compreensão" (Morin, 2003). Este revela a importância de centrar a sociedade na pessoa que desenvolve, simultaneamente, responsabilidades individuais e sociais, o que "inclui, necessariamente, um processo de empatia, de identificação e de projeção" (Morin, 2003, p. 95). Portanto, o processo de construção do conhecimento deve, também, fornecer ao aluno competências que valorizem afetividade e interação.

De modo a responder a estes novos desafios educacionais emergiram várias metodologias pedagógicas com base nas Tecnologias Digitais de Informação e Comunicação (TDIC). Diversos estudos referem as vantagens da aprendizagem híbrida (blended learning) (Boelens et al., 2017) e reconhecem-lhe o potencial para renovar as práticas letivas, enquanto modalidade dinâmica que envolve diferentes abordagens pedagógicas, tecnologias e espaços de aprendizagens. Uma dessas abordagens é a "Sala de Aula Invertida" (SAI), que contempla atividades online e presenciais e inverte uma série de variáveis curriculares da aula tradicional, como objetivos educacionais, tempos, espaços e papéis de alunos e professores (Bergmann \& Sams, 2012). Neste âmbito, torna-se pertinente investigar de que modo a implementação de um modelo de aprendizagem híbrida contribui para operacionalizar os princípios do PAFC. Além disso, este estudo atende a uma sugestão de revisões de literatura sobre SAI que refere a necessidade de melhoria do design das propostas SAI a implementar para melhorar a satisfação dos alunos com à abordagem (Van Alten et al., 2019).

Assim, através da metodologia investigação-ação, conduzimos um estudo cujo objetivo era analisar de que modo uma proposta SAI modifica/ inova a realidade escolar para potenciar a aprendizagem dos alunos através de uma formação humanista que respeite os princípios do PAFC. Mais concretamente, pretendíamos responder a duas questões de investigação (QI):

QI1: Qual o efeito da implementação da proposta SAI no envolvimento e na aprendizagem dos alunos?

QI2: Se a implementação da proposta SAI provocou alterações no processo de aprendizagem, em que medida essas alterações estão alinhadas com os princípios do PAFC?

Os conhecimentos produzidos no âmbito desta avaliação permitirão melhorar a proposta a implementar em intervenções futuras e contribuir para o desenvolvimento de uma formação escolar com visão de futuro. 


\section{ENQUADRAMENTO TÉORICO}

\subsection{PROJETO DE AUTONOMIA E FLEXIBILIDADE CURRICULAR (PAFC)}

O PAFC em curso nas escolas portuguesas, desde o ano letivo (2017-2018), constitui uma política de mudança curricular assente na transformação gradual das lógicas organizacionais e pedagógicas do trabalho da escola e dos professores (Roldão \& Almeida, 2018).

Apoiado num conjunto de documentos de referência: o Perfil dos Alunos à Saída da Escolaridade Obrigatória (PA); um referencial do currículo dos ensinos básico e secundário, centrado em Aprendizagens Essenciais e uma Estratégia Nacional de Educação para a Cidadania, permite que as escolas configurem um currículo mais adequado às especificidades da população escolar.

Trata-se, portanto, de conceber uma "escola inclusiva, cuja diversidade, flexibilidade, inovação e personalização respondem à heterogeneidade dos alunos, eliminando obstáculos de acesso ao currículo e às aprendizagens, adequando estas ao perfil dos alunos" (Despacho $\mathrm{n}^{\mathrm{o}}$ $5908 / 2017,5$ de julho, 2017, p. 13883).

Nesse sentido, a gestão autónoma e flexível do currículo, regulada pelos elementos curriculares emanados pelo Ministério da Educação, atende a um conjunto elencado de recomendações que alteram, inevitavelmente, muitas das práticas organizacionais e pedagógicas enraizadas nas escolas.

Uma dessas recomendações consiste em priorizar práticas colaborativas entre professores promotoras da interdisciplinaridade e articulação do currículo. 0 resultado dessa articulação são percursos pedagógicos integradores, que transcendem e contrariam as abordagens disciplinares, para permitir uma compreensão global de temas e ideias (UNESCO-BIE, 2016).

Além de contextualizados, esses percursos pedagógicos devem ser orientados para o desenvolvimento integral e efetivo dos alunos (Rodrigues, 2018), pois ao traçar um PA, o PAFC define o que se pretende que os jovens alcancem no final do seu percurso escolar. Este perfil de base humanista revela a importância de centrar a sociedade na pessoa que desenvolve responsabilidades individuais e sociais. São estas responsabilidades, desenvolvidas em contexto escolar, que permitem aos jovens compreender a realidade vivenciada pelo outro, ser mais solidário e ter atitudes mais democráticas para o exercício de uma cidadania ativa (Despacho $\mathrm{n}^{\mathbf{o}}$ 6478/2017, 26 de julho, 2017). Nesse sentido, a lógica de conceção das atividades pedagógicas deve ser centrada na aprendizagem do aluno com vista à aquisição do conjunto de competências promotoras do exercício da cidadania ativa, de participação social em contextos de partilha e de colaboração.

As opções curriculares que permitem adquirir essas competências são feitas com base nas aprendizagens essenciais que resultam do "emagrecimento" do currículo e do aprofundamento das aprendizagens consideradas estruturantes (Roldão \& Almeida, 2018, p. 45). Um currículo baseado em aprendizagens essenciais pode favorecer a otimização do tempopedagógico-didático disponível para promover essas mesmas aprendizagens, de uma forma inclusiva e diferenciada (Rodrigues, 2018). Essa otimização pode ser conseguida com a criação de cenários educativos estimulantes e criativos, que tenham em conta a diversidade dos alunos e os seus ritmos, que falem a linguagem dos estudantes de hoje (sempre conectados e adeptos 
da tecnologia), e que permitam desenvolver, com uma orientação mais eficaz do professor, as competências que vão ao encontro do PA.

\subsection{BLENDED LEARNING}

0 atual processo de transformação da escola, aliado a uma perspetiva de desenvolvimento tecnológico, exige a criação de modelos educacionais apoiados em currículos que realcem a realidade multifacetada, multidimensional e multidisciplinar para promover uma aprendizagem que responda aos desafios da sociedade contemporânea (Monteiro et al., 2015).

Nesse sentido, os princípios do PAFC permitem otimizar percursos formativos que reconhecem ao aluno o papel de construtor do seu conhecimento com apropriação das suas aprendizagens. A ênfase recai numa aprendizagem centrada no aluno que resulta da combinação de dois conceitos afins, o ensino personalizado e a aprendizagem baseada na competência (Horn \& Staker, 2015).

Nesta visão de escola, a tecnologia assume um papel fundamental pois suporta a construção de um modelo inovador, flexível e abrangente no sentido de integrar diferentes espaços e tempos de aprendizagem, permitindo que o ensinar e o aprender aconteçam através de uma interligação simbiótica e constante entre mundo físico e mundo digital (Morán, 2015).

Falamos, pois, de uma visão blended (híbrida) que alia a presença física à exploração do potencial das aprendizagens em rede, mediadas pelas tecnologias, e que reconhece que a educação não só acontece na sala de aula, mas em múltiplos espaços, incluindo os virtuais, desenvolvendo nos alunos um sentido de atuação, propriedade pelo seu progresso e capacidade de conduzir a sua aprendizagem.

Portanto, a modalidade blended learning (aprendizagem híbrida) quando bem implementada é a base de um modelo de aprendizagem centrado no aluno (Horn \& Staker, 2015), tal como preconiza o PAFC.

0 blended learning (b-learning) pode ser definido como um programa de educação formal no qual, o aluno aprende através da combinação da aprendizagem online com a aprendizagem presencial (Horn \& Staker, 2015). No online, os conteúdos disponibilizados devem permitir ao aluno algum controlo sobre a sua aprendizagem, quer seja através do tempo, lugar, caminho ou ritmo. A parte presencial, supervisionada pelo professor, deve estar intimamente relacionada com os conteúdos disponibilizados online, de modo a proporcionar ao aluno uma experiência integrada de aprendizagem (Horn \& Staker, 2015).

No entanto, o b-learning é mais do que a integração de momentos presenciais e não presenciais, é uma modalidade dinâmica que promove uma série de interações, envolve diferentes abordagens pedagógicas, diferentes tecnologias e espaços de aprendizagens e, para ser bem-sucedida, não pode descurar as componentes afetivas e sociais (Silva et al., 2017).

O Relatório do Instituto Clayton Christensen intitulado "Blended Beyond Borders: A scan of blended learning obstacles and opportunities in Brazil, Malaysia, \& South Africa", de 2017, aponta o b-learning como a chave para a renovação das práticas escolares, dinamizadora de um ensino mais personalizado e diferenciado, desde que as duas modalidades de aprendizagem estejam conectadas, de modo a fornecer uma experiência integrada, o que pode significar o uso de dados da aprendizagem online para informar ou dirigir a aprendizagem offline do aluno (Fisher et al., 2017). 
Os resultados desta pesquisa, cujo objetivo era investigar o processo de implementação do b-learning em 263 escolas públicas e privadas do Brasil, Malásia e Africa do Sul, evidenciaram que apesar do processo de implementação do b-learning ainda enfrentar muitos obstáculos, já começa a produzir alguma cultura de inovação nas escolas. A par das infraestruturas tecnológicas e a conectividade, o capital humano representa o maior desafio à implementação do b-learning. Portanto, capacitar os professores para a inovação com as tecnologias parece ser o fator determinante para incrementar todo o potencial educativo do $b$-learning.

Embora a implementação, bem-sucedida, do b-learning seja um processo complexo que exige uma reengenharia dos processos de aprendizagem e mudanças culturais nas instituições e nos atores (Monteiro et al., 2015), existem vários modelos do b-learning, mais ou menos disruptivos em relação à sala de aula tradicional. Um deles é a Flipped Classroom (sala de aula invertida) que usa a tecnologia, através da aprendizagem online para melhor responder às atuais necessidades dos alunos.

\subsection{SALA DE AULA INVERTIDA: DESIGN DE UMA PROPOSTA DE IMPLEMENTAÇÃO DO B-LEARNING}

A Sala de Aula Invertida (SAI) ou "Flipped Classroom" (Bergmann \& Sams, 2012) apresenta-se como um modelo de implementação do b-learning, muito adotado em educação, pois concentra informações básicas e factuais em ambientes virtuais e permite que em sala de aula, os alunos desenvolvam tarefas mais elaboradas, criativas e orientadas, através da combinação de aprendizagem por desafios, projetos, problemas reais e jogos (Morán, 2015).

Investigações anteriores sobre SAI indicam que o facto de os alunos receberem os conteúdos instrucionais, antes da aula, acarreta uma série de benefícios pedagógicos. Centra a aprendizagem no aluno (McLaughlin et al., 2013) responsabilizando-o pela exploração dos materiais disponibilizados e pela preparação da aula online. Quando esses materiais são vídeos pedagógicos, os alunos podem controlar a sua aprendizagem através do número de vezes que observam o vídeo e do ritmo de visualização (Ribeirinha \& Silva, 2020). O estudo autónomo inicial pode ter efeitos positivos na capacidade de autorregulação das aprendizagens (Lape et al., 2014) e na mudança de hábitos de aprendizagem. Porém, a principal vantagem da SAI é o aumento do tempo disponível para as atividades/interações presenciais (DeLozier \& Rhodes, 2017), o que se poderá traduzir em mais oportunidades de interação com os pares e com o professor, de praticar e aplicar conhecimentos.

Nos Estados Unidos existe uma organização, a Flipped Learning Network (FLN), que divulga informações para que este modelo possa ser implementado com sucesso. O Flipped Classroom Field Guide (Flipped Learning Network, 2014) aponta quatro recomendações para inverter a sala de aula:

1) Os ambientes de aprendizagens online e presencial são altamente estruturados e planeados;

2) Os alunos são incentivados a participar nas atividades online e presencial, pois a sua participação é valorizada na avaliação formal; 
3) Na sala de aula as atividades propostas envolvem aprendizagens ativas, obrigando o aluno a recuperar, aplicar e ampliar o material estudado online;

4) Os alunos recebem feedback do professor após a realização das atividades online e presenciais.

Seguindo as recomendações descritas, bem como as de outros autores (Bishop \& Verleger, 2013; Lo \& Hew, 2017), apresenta-se, de seguida, a proposta SAI implementada neste estudo. A proposta apresenta duas componentes, a aula online, a realizar em casa, individualmente pelo aluno, seguindo-se a aula presencial a realizar na escola, no horário estabelecido para a disciplina.

Para a aula online, testaram-se algumas plataformas de aprendizagem, tendo a escolha recaído na plataforma educativa Edmodo (new.edmodo.com), por ter um ambiente de aprendizagem amigável, suportar aplicações multimédia (como vídeos) e assegurar a comunicação entre todos os participantes.

Os conteúdos programáticos foram disponibilizados, na plataforma, sob a forma de vídeos didáticos. Na sua elaboração foram tidos em conta os princípios da Teoria Cognitiva da Aprendizagem Multimédia (Mayer, 2001), nomeadamente, na duração e segmentação do vídeo, simplicidade, destaque de informações e linguagem usada.

Para promover uma maior interação dos alunos com os vídeos adicionaram-se outras estratégias: era lhes pedido para tirar notas (esta ação era auxiliada por uma listagem de conteúdos abordados ao longo do vídeo), para refletir sobre as questões colocadas ao longo do vídeo e responder a um quiz de quatro questões. Os quizzes foram elaborados na plataforma Edmodo e as suas questões incidiam sobre os conteúdos do vídeo, que atendendo à taxonomia de Bloom revista (Krathwohl, 2002), estavam organizadas por ordem crescente de complexidade: a questão um enquadrava-se na dimensão do processo cognitivo "lembrar", a dois no "entender", a três em "aplicar" e a quarta em "analisar".

Assim, a aula online, disponibilizada no mínimo com 72 horas antes da aula presencial, era composta pelo vídeo didático, uma listagem de conteúdos associada ao vídeo, a indicação das páginas do manual onde se encontravam os conteúdos e um quiz.

A submissão do quiz, por cada aluno, devia ser feita até 12 horas antes da aula presencial para dar feedback ao professor sobre que aspetos devia mais incidir na aula presencial.

$\mathrm{Na}$ aula presencial, os primeiros minutos eram reservados para o diálogo sobre os conteúdos do vídeo, o esclarecimento dos aspetos que suscitaram dúvidas e a análise das respostas do quiz. Por aula, eram propostas aos alunos diversos tipos de atividades, intercalando trabalho individual e de grupo, desde resolução de exercícios do manual adotado, exploração de simulações com o respetivo quiz de monitorização e resolução de problemas. Nas atividades de grupo, a turma era divida em cinco grupos, que por rotação por estações de aprendizagem (Horn \& Staker, 2015), iam fazendo as tarefas, apoiados pelo professor.

A avaliação formativa das aprendizagens era realizada no final da semana, através de um teste formativo escrito. Os testes formativos (T) pretendiam aferir o trabalho desenvolvido pelo aluno, tendo sido estruturados num formato semelhante ao dos quizzes (quatro questões de escolha múltipla organizadas por ordem crescente de complexidade). Os 
alunos responderam a três testes formativos ao longo das três semanas: na primeira semana, o T1 que incidia sobre os conteúdos do quiz 1e 2; na segunda semana, o T2 que incidia sobre os conteúdos do quiz 1, 2, 3 e 4, e, na terceira semana, o T3 que incidia sobre os conteúdos do quiz 1, 2, 3, 4 e 5.

\section{METODOLOGIA DE INVESTIGAÇÃO}

\subsection{PROCEDIMENTOS DE INVESTIGAÇÃO}

0 processo de investigação empírica do presente estudo usou uma metodologia de Investigação-Ação (I-A) que consiste no estudo de uma situação social com o objetivo de melhorar a ação que nela decorre (Elliott, 1991 p. 69). É uma forma de investigação efetuada pelos próprios participantes, de cariz colaborativo e autorreflexivo, induzida pela necessidade de compreensão e mudança de certas práticas sociais ou educacionais (Kemmis, 2007).

0 processo de I-A é cíclico e dinâmico, pois apresenta um diálogo permanente entre a ação e a reflexão. Desenvolve-se em quatro fases (planificação, ação, observação e reflexão), a partir das quais se podem delinear novos ciclos (Kemmis, 2007). Inicia-se com o desenvolvimento de um plano de ação a propósito de um problema relevante, contempla o design da ação, em termos de questões de pesquisa, aspetos metodológicos e protocolo de avaliação. Os efeitos da ação, revestidos da necessária contextualização, são documentados a partir da observação e reflexão. Essa reflexão é o ponto de partida para uma nova planificação que dará início a um novo ciclo investigativo.

A projeção de novos ciclos prende-se com a necessidade do professor/ investigador explorar e analisar consistentemente, com olhar retrospetivo e prospetivo (Coutinho et al., 2009), todas as interações ocorridas durante o processo o que gera uma "espiral autorreflexiva" (Kemmis, 2007, p. 168) de conhecimento e ação.

Esta metodologia sustenta a criação de "comunidades críticas" (Kemmis, 1993) de investigação, pois, é a colaboração entre as partes envolvidas no processo investigativo, associada a uma intervenção de caracter dinâmico e personalizado que possibilita o debate e a confrontação dos registos documentados durante a fase de ação, para uma melhor compreensão da situação, aproximando a realidade educativa do ato investigativo (Coutinho et al., 2009).

\subsection{INSTRUMENTOS}

No sentido de proceder à reflexão/avaliação da ação desenvolvida, a metodologia I-A recorre a uma variedade de técnicas de recolha de evidências que asseguram a credibilidade do estudo (Coutinho et al., 2009).

Assim, neste estudo foram usados dois questionários. 0 questionário um (Q1), aplicado no dia 4/02/20, para o estudo do contexto, destinado a recolher informações que possibilitassem um melhor conhecimento dos alunos, relativamente ao uso e integração da tecnologia nos seus métodos de estudo e trabalho, na disciplina onde a pesquisa se realizou (Física e Química, F.Q., 10ำ ano). Para a sua estruturação foi criado um plano metodológico baseado em três grandes áreas de informação (Perfil do aluno que frequenta a disciplina, Recursos TDIC e funcionalidades usadas no dia a dia e Integração das TDIC na aprendizagem da F.Q.) concretizadas através de 19 indicadores. 
As questões, num total de 21, eram, maioritariamente, do tipo fechado e de resposta obrigatória.

O questionário dois (Q2), aplicado no dia 12/03/20, destinado a recolher informações sobre as perceções dos alunos face ao modelo implementado. O Q2 era constituído, maioritariamente, por questões do tipo fechado (15 questões), de preenchimento obrigatório, minimizando assim a taxa de respostas incompletas. Tinha também questões de resposta aberta onde era pedida uma avaliação global de cada componente (online e presencial) e do modelo SAI.

Ambos os questionários foram submetidos à validação do seu conteúdo por três especialistas universitários da área académica da Tecnologia Educativa e realizou-se um pré-teste com três alunos de $10^{\circ}$ ano, cujas sugestões apresentadas permitiram completar e reestruturar algumas questões.

Para além dos questionários foram também utilizados os resultados dos cinco quizzes e os três testes formativos.

\subsection{PARTICIPANTES E CONTEXTO DE ESTUDO}

O consentimento para a realização do estudo foi concedido por todos os participantes através do documento de consentimento informado, esclarecido e livre para participação em estudos de investigação.

A pesquisa decorreu numa turma de 10. ano do ensino secundário, na disciplina de F.Q., ao longo de três semanas, o que correspondeu a 20 horas de interação com a turma, em contexto sala de aula.

Os dados que a seguir se apresentam resultaram da aplicação do Q1 a todos os alunos da turma e permitiram uma caracterização dos alunos e do contexto de aprendizagem, antes da realização da pesquisa.

Os participantes são 22 alunos, 10 alunos são do sexo feminino e 12 do sexo masculino, a média de idades é de 15,05 anos e não existem alunos com retenções.

Todos os alunos têm dispositivos de acesso à internet em casa e passam em média, mais de três horas online. As três funcionalidades/aplicações mais usadas online, são as "Redes Sociais" (82\%), "Músicas" (77\%) e os "Vídeos" (73\%).

O desempenho dos alunos na disciplina de F.Q. está maioritariamente entre o Razoável e Bom (91\%) estando 4,5\% no Muito Bom e 4,5\% no Mau. As razões mais votadas que condicionam positivamente o desempenho dos alunos na disciplina de F.Q. foram: "Gosto pela disciplina" $(63,6 \%)$ e "Interesse prático dos temas abordados" (50\%). Pelo contrário, as razões mais votadas que condicionam negativamente o seu desempenho foram: "Complexidade dos temas tratados" (36,4\%) e "Falta de empenho" $(36,4 \%)$.

As três estratégias de estudo mais usadas são a "Resolução de exercícios" (95\%) a "Consulta do manual" (73\%) e "Falar da matéria com os meus colegas" (68\%).

No que se refere às preferências dos alunos em termos de metodologia de aprendizagem na disciplina de F.Q., de uma listagem de 11 itens, os alunos são unânimes em considerar o "Trabalho laboratorial" (100\%) como a metodologia mais indicada, seguida da "Explicação do professor" (95\%) e os "Trabalhos em grupo" e o "Recurso às TDIC pelo professor" ambos em terceiro lugar com $91 \%$ das preferências.

Quanto ao modo como a tecnologia estava a ser usada na disciplina de F.Q. as três utilizações mais frequentes são: "Apresentações digitais de 
conteúdos didáticos pelo professor", "Apresentações digitais de trabalhos realizados pelos alunos" e "Comunicação com os alunos (emails)". Relativamente à utilização das TDIC em casa para estudo, 72,7\% dos alunos dizem que nunca usou.

Face a esta caracterização, considerou-se que a turma reunia as condições necessárias à implementação do modelo SAI.

\section{RESULTADOS}

\subsection{DADOS QUANTITATIVOS - QUESTÕES FECHADAS DO Q2}

As respostas dos alunos ao questionário foram englobadas em três grandes áreas de informação, a aula online, a aula presencial e o modelo SAI (tabela 1).

Tabela 1

Respostas dos alunos, em percentagem, aos itens do Q2

\begin{tabular}{|c|c|c|c|c|c|}
\hline Item & \multicolumn{5}{|c|}{ Escala } \\
\hline \multicolumn{6}{|l|}{ Aula online (AO) } \\
\hline & 1 & 2 & 3 & 4 & 5 \\
\hline Frequência de preparação da aula online & & 4,5 & & 27,3 & 68,2 \\
\hline $\begin{array}{l}\text { As estratégias “Discussão dos vídeos e Q\&A na aula presencial” } \\
\text { tornaram importante a preparação da aula online }\end{array}$ & & & 9,1 & 36,3 & 54,6 \\
\hline Satisfação na preparação da aula online & & & 18,1 & 50,0 & 31,9 \\
\hline A preparação prévia da aula online é útil para a aprendizagem & & & 13,6 & 40,9 & 45,5 \\
\hline Contribuição da aula online para a aprendizagem dos conteúdos & & & & 50,1 & 49,9 \\
\hline \multicolumn{6}{|l|}{ Aula presencial (AP) } \\
\hline A preparação da $\mathrm{AO}$ permitiu a realização de mais atividades & & & 9,1 & 40,9 & 50,0 \\
\hline A preparação da AO permitiu o esclarecimento de mais dúvidas & & & 22,7 & 22,7 & 54,6 \\
\hline $\begin{array}{l}\text { Ordenação de atividades, desenvolvidas, em função do grau de } \\
\text { interesse/participação }\end{array}$ & \multicolumn{5}{|c|}{$\begin{array}{c}1^{\circ} \text { trabalho de grupo } \\
2^{\circ} \text { exploração de simulações } \\
3^{\circ} \text { atividades } Q \& A\end{array}$} \\
\hline Satisfação com as atividades desenvolvidas & & & 9,1 & 18,2 & 72,7 \\
\hline $\begin{array}{l}\text { A rotação dos grupos por diferentes atividades tornou a aula mais } \\
\text { dinâmica }\end{array}$ & 4,5 & & 4,5 & 27,3 & 63,7 \\
\hline $\begin{array}{l}\text { As simulações permitiram visualizar, na prática, os conteúdos } \\
\text { explorados nos vídeos }\end{array}$ & & & 4,5 & 40,9 & 54,6 \\
\hline Nestas aulas os alunos tiveram um papel mais ativo & & 4,5 & 9,1 & 22,7 & 63,7 \\
\hline Permitiu consolidar e ampliar as aprendizagens iniciadas na AO & & & 9,2 & 45,4 & 45,4 \\
\hline Senti-me apoiado tanto pela professora como pelos meus colegas & & 4,5 & 13,6 & 27,3 & 54,6 \\
\hline \multicolumn{6}{|l|}{ SAI } \\
\hline Empenho nas atividades implementadas & & & 9,1 & 45,4 & 45,5 \\
\hline Satisfação & 4,5 & & 13,6 & 18,2 & 63,7 \\
\hline Respeito pelo ritmo de aprendizagem & & 4,5 & 9,1 & 27,3 & 59,1 \\
\hline Permite uma melhor compreensão dos conteúdos & & 4,5 & 13,6 & 27,3 & 54,6 \\
\hline Possibilidade de aprender com as explicações dos colegas & 4,5 & 4,5 & 18,2 & 36,4 & 36,4 \\
\hline
\end{tabular}

Escala: 1(Discordo totalmente), 2(Discordo em parte), 3(Não concordo nem discordo), 4 (Concordo, C), 5(Concordo totalmente, CT).

$\mathrm{Na}$ frequência de preparação variou entre 1(Nunca) a 5 (Sempre). No empenho nas atividades variou entre 1(Muito Mau) 5 (Muito Bom)

Observando a tabela 1, verifica-se que uma elevada percentagem de alunos preparou a AO (96\% Sempre ou Quase Sempre), o que poderá terse devido à incorporação de estratégias que favoreceram a sua preparação (91\% C ou CT que as estratégias tornaram importante a preparação da A0) mas, também, à forma como estas foram estruturadas, o que, possivelmente, contribuiu para a perceção dos alunos sobre a eficácia da AO na 
aprendizagem $(100 \%$ C ou CT com a contribuição da AO para a aprendizagem dos conteúdos). No entanto, apesar dos alunos exprimirem concordância com a utilidade de preparação prévia da aula online ( $86 \%$ C ou CT), a satisfação na preparação da AO é o indicador com menor percentagem ( $82 \%$ C ou CT).

A utilidade de preparação da AO parece estar relacionada com a quantidade de atividades realizadas na AP, sendo essa a consequência mais votada pelos alunos ( $91 \%$ C ou CT). Dos vários tipos de atividades desenvolvidas na AP, as atividades de grupo e a exploração de simulações foram as mais destacadas pelo grau de interesse e participação que provocaram nos alunos. A complementaridade com a AO $(96 \%$ concorda que a exploração de simulações permitiram visualizar, na prática, os conteúdos explorados nos vídeos e 91 \% concorda que a AP permitiu consolidar e ampliar as aprendizagens iniciadas na AO) associada ao dinamismo criado com a rotação dos grupos pelas diferentes atividades (91 \% C ou CT que a rotação dos grupos por diferentes atividades tornou a aula mais dinâmica) poderá ter-se traduzido na percentagem de alunos satisfeitos com as atividades desenvolvidas ( $91 \%$ C ou CT, sendo que 73\% CT).

Não obstante, os itens da AP que apresentam maior dispersão nas percentagens de resposta são: nestas aulas os alunos tiveram um papel mais ativo $(86,4 \% \mathrm{C}$ ou CT embora $64 \% \mathrm{CT})$ e senti-me apoiado tanto pela professora como pelos meus colegas ( $81 \%$ C ou CT embora $55 \%$ CT).

Analisando globalmente a implementação do modelo SAI é de salientar o elevado grau de empenho dos alunos nesta unidade (91\% classificou-o de Bom ou Muito Bom) e o respeito pelo ritmo de aprendizagem dos alunos foi a característica do modelo com maior percentagem de concordância (86\% C ou CT).

\subsection{DADOS QUALITATIVOS - QUESTÕES ABERTAS DO QUESTIONÁRIO}

A análise de conteúdo realizada ao discurso dos alunos nas questões abertas do questionário permitiu identificar categorias de análise comuns, presentes nas três grandes áreas de informação e a sua frequência relativa (número de unidades de registo codificadas numa categoria divido pelo número total de unidades de registo) permitiu a construção dos gráficos da figura 1 e 2 . 
Figura 1

Gráfico de barras da frequência relativa das categorias presentes no discurso dos alunos sobre a $A O$ e $A P$

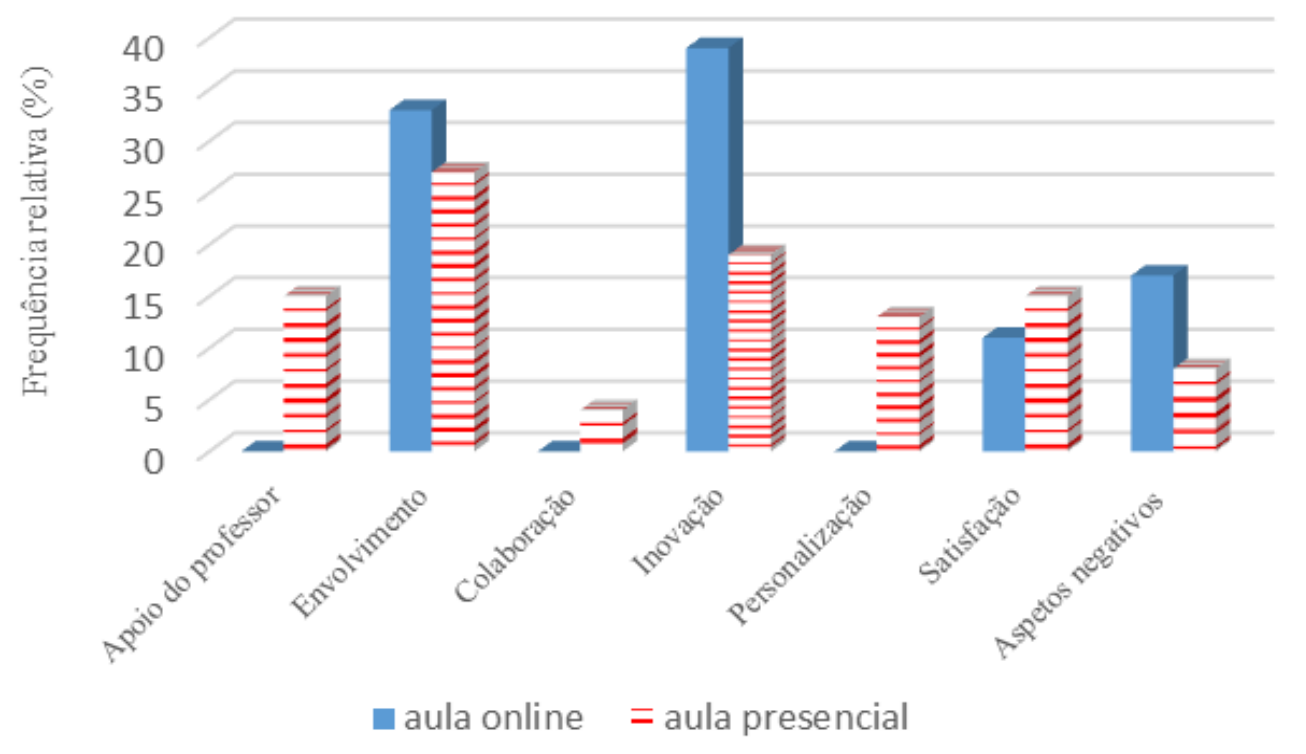

A análise de conteúdo do discurso dos alunos sobre AP fez emergir um maior número de categorias quando comparada com a AO (figura 1). No entanto, a inovação (descrita pelo modo como o professor planeia novas e diferentes atividades em aula, técnicas de ensino e formas de avaliação) e o envolvimento (descrito por aspetos relacionados com a atenção, interesse e a participação dos alunos nas atividades) são categorias transversais às duas componentes do modelo SAI com maior frequência no discurso dos alunos.

Figura 2

Gráfico circular da frequência relativa das categorias presentes no discurso dos

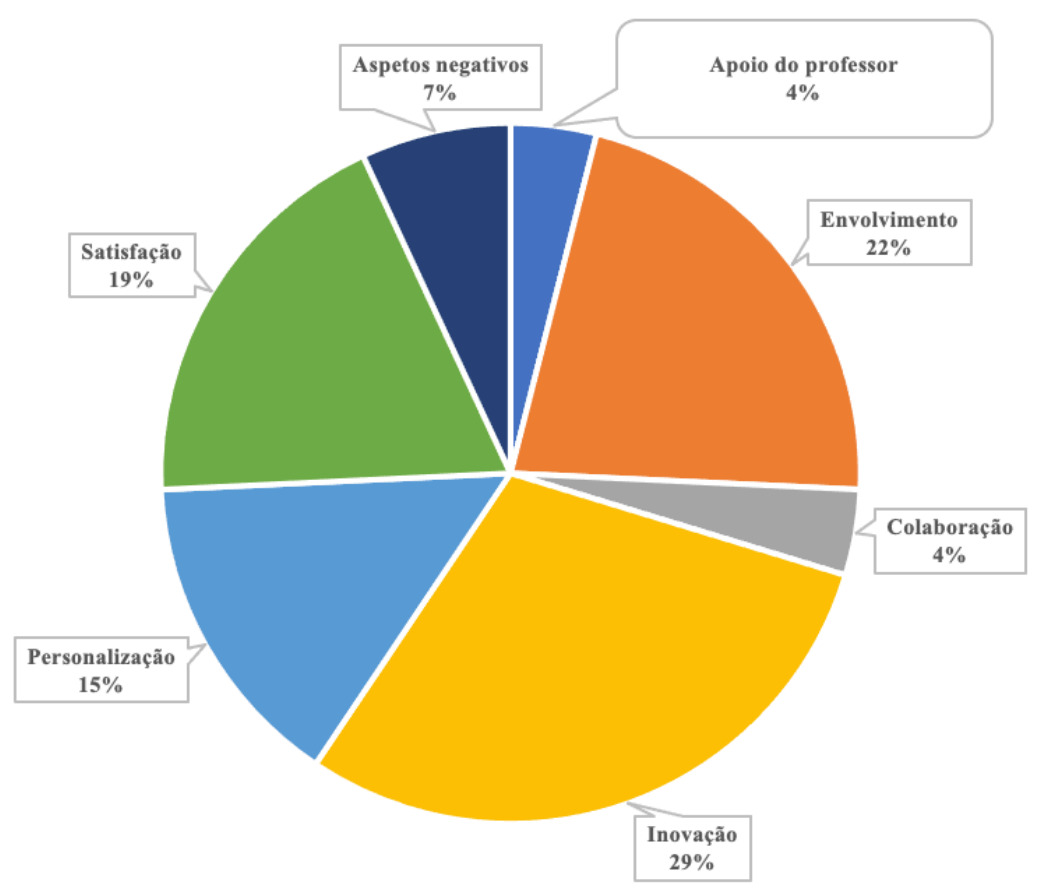

alunos sobre a SAI

Na avaliação global do modelo SAI (figura 2) são identificadas várias categorias no discurso dos alunos, tal como acontece na AP (figura 1). 
Além da inovação e envolvimento destaca-se a satisfação (descrita por aspetos relacionados com a motivação dos alunos para aprenderem, o gosto pelo tipo de aulas e o seu bem-estar) com o modelo e a personalização (relacionado com a tratamento diferenciado dos alunos, de acordo com as suas competências, interesses e ritmos de trabalho). Embora esta categoria não tenha grande frequência na componente online está, de certo modo, relacionada com o envolvimento, pois um maior envolvimento dos alunos com as tarefas propostas, pode ser uma consequência de uma estruturação das tarefas atenta às suas necessidades.

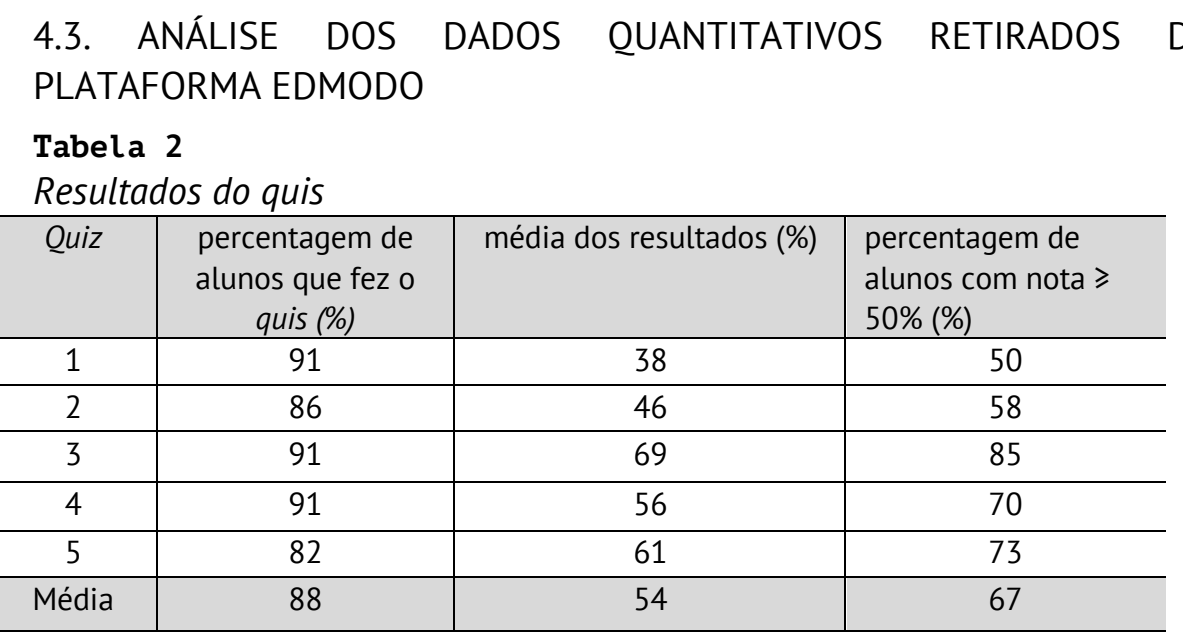

Verifica-se uma elevada percentagem na média de alunos que realizou todos os quizzes (88\%). A média dos resultados do quizzes (54\%) evidencia que os alunos fizeram uma preparação satisfatória da aula online, mais concretamente, em média, $67 \%$ dos alunos obtiveram nos quizzes uma nota igual ou superior a $50 \%$, ou seja, acertaram em pelo menos duas, das quatro questões do quiz.

\subsection{ANÁLISE DOS TESTES FORMATIVOS}

Tabela 3

Resultados dos testes formativos

\begin{tabular}{c|c|c}
\hline $\begin{array}{l}\text { Testes } \\
\text { formativos }\end{array}$ & $\mathrm{N}$ & média dos resultados (pontos*) \\
\hline 1 & 21 & 116 \\
\hline 2 & 20 & 138 \\
\hline 3 & 21 & 134 \\
\hline Média & 21 & 129 \\
\hline${ }^{*}$ escala de 0 a 200 pontos \\
\hline
\end{tabular}

Todos os testes formativos, em média, apresentam resultados superiores a 100 pontos e a sua média global é de 129 pontos. Estes resultados, quando comparados com os resultados dos quizzes, permitiram averiguar se as interações produzidas na AP se refletiram nos resultados dos alunos, ou seja, se as interações produzidas envolveram os alunos em atividades que desenvolveram os níveis superiores da taxonomia. Nessa comparação, consideramos apenas os resultados dos alunos que realizaram todos os quizzes e testes formativos $(\mathrm{N}=13)$ e os resultados da média dos quizzes por aluno foram convertidos na mesma escala dos testes formativos. Em termos práticos colocamos a seguinte hipótese: A média dos quizzes antes 
das interações é menor do que a média dos testes formativos realizados após as interações em sala de aula. Pretendíamos, portanto, comparar as médias de duas distribuições normais [a normalidade dos dados foi garantida pelo teste Shapiro-Wilk: S-W(quiz) =0,9518; $p=0,626$ e S-W(teste) $=0,937 ; p=0,415]$, da mesma população, mas em dois momentos diferentes: antes e após as interações em sala de aula. Aplicamos o teste-t de diferenças entre médias populacionais para dados emparelhados e cujo resultado se apresenta na tabela 4.

Tabela 4

Resultados da aplicação do teste-t

\begin{tabular}{c|c|c}
\hline \multicolumn{3}{|c|}{ teste- $t$} \\
\hline $\mathrm{N}$ & Quizzes & Teste formativos \\
\hline Média & 13 & 13 \\
\hline Desvio padrão & 106 & 35 \\
\hline $\mathrm{t}$ & 36 & $-2,348$ \\
\hline $\mathrm{t}$ (crítico uni-caudal) & \multicolumn{3}{|c}{1,782} \\
\hline$p$ & \multicolumn{3}{|c}{0,0368} \\
\hline
\end{tabular}

Com base na análise dos resultados do teste-t, a média dos resultados dos quizzes é estatisticamente diferente da média dos resultados dos testes formativos $(t(12)=-2,348 ; p=0,0368)$. Assim, com $95 \%$ de confiança, aceitamos a hipótese formulada de que a média dos quizzes foi inferior à média dos testes formativos.

\subsection{DISCUSSÃO DOS RESULTADOS}

A leitura cruzada dos dois questionários, combinada com os dados extraídos da plataforma e os resultados dos testes formativos, permite fazer uma análise mais contextualizada e discutida dos resultados obtidos, e assim, responder às questões de investigação.

Q11: Qual o efeito da implementação da proposta SAI no envolvimento e na aprendizagem dos alunos?

Um dos maiores problemas relacionados com a implementação da SAI, reportados na literatura, é a falta de envolvimento dos alunos com a aula online, cuja causa poderá ser a não familiarização com a abordagem de aprendizagem online, o que conduz à não realização das tarefas (Lo \& Hew, 2017). Nesta turma, o envolvimento dos alunos com as tarefas propostas na AO ficou evidenciado pela elevada taxa de preparação da AO ( $96 \%$ S ou QS), pelos resultados da análise do discurso dos alunos, no qual o envolvimento foi a segunda categoria mais frequente (gráfico 1) e pela elevada média de concretização dos quizzes (88\%). Dos fatores que mais contribuíram para esse envolvimento destacam-se as estratégias implementadas $(91 \%$ de concordância) e a complementaridade da AO com AP (91 \% de concordância).

No entanto, quando não existe a devida orientação e apoio do professor alguns alunos exibem comportamentos pouco autorregulados e agem com pouca responsabilidade (Sun et al., 2017) o que provavelmente afetará as atividades a desenvolver na aula presencial. A orientação é, portanto, fundamental, pois fomenta um maior envolvimento dos alunos, reduz a carga cognitiva associada à tarefa (Kirschner et al., 2006) e permite que os alunos ativamente gerem aprendizagens significativas através do estabelecimento de relações com os conceitos estudados autonomamente. 
Nesse sentido, destaca-se o apoio do professor na aula presencial (81 \% de concordância no Q2, e uma das categorias mais frequentes na análise do discurso dos alunos sobre a AP) que ao ser conjugado com propostas didáticas, que tiveram em consideração as preferências dos alunos, indicadas no Q1 ("Explicação do professor" (95\%) os "Trabalhos em grupo" e o "Recurso às TDIC pelo professor"), parece ter criado condições para um maior envolvimento dos alunos. Portanto, ao serem implementadas simulações computacionais, associadas às tarefas em grupo, apoiadas pelo professor, gerou-se a satisfação dos alunos com a aula presencial (91\% de concordância e com frequência relevante na análise de discurso sobre a AP) o que, possivelmente, potenciou o envolvimento (categoria mais frequente na análise de discurso sobre a AP).

Aliando a predisposição natural dos alunos face à disciplina de F.Q (91\% dos alunos classificou o seu desempenho de Satisfatório ou Bom, 63,6\% gostam da disciplina e 50\% tem interesse pelos temas abordados) com a complementaridade das atividades implementadas nas duas componentes, suportada pelo modo de atuação do professor, se possa explicar que, após a implementação da proposta SAI, $91 \%$ dos alunos classifique o seu empenho de B ou MB, quando no Q1 a "falta de empenho" $(36,4 \%)$ era indicado como um dos fatores que condicionava negativamente o desempenho dos alunos na disciplina.

Concluímos, portanto, que a proposta SAI implementada proporcionou uma experiência integrada de aprendizagem e potenciou o envolvimento dos alunos na aprendizagem. Resultados semelhantes são descritos por Gross et al. (2015) que conseguiram aprimorar o envolvimento dos alunos e a sua satisfação com o curso ao usarem a abordagem SAI.

Relativamente à aprendizagem e baseando-nos na taxonomia de Bloom revista (Krathwohl, 2002), argumenta-se que o professor, ao disponibilizar online os materiais didáticos, permite que o aluno desenvolva as dimensões cognitivas de nível inferior da taxonomia, o lembrar e entender, libertando mais tempo em sala de aula, para envolver os alunos em atividades que desenvolvam as dimensões dos níveis superiores da taxonomia (Bergmann \& Sams, 2012). Nesse sentido, ao estruturarmos as quatro questões dos quizzes por níveis de aprendizagem, a média dos resultados dos quizzes, 54\%, evidencia que os alunos fizeram uma preparação satisfatória da AO. Na análise por quiz verifica-se que em média, $67 \%$ dos alunos conseguiram acertar pelo menos duas questões. Estes dados sustentam a ideia que a AO permitiu que mais de metade dos alunos, de forma autónoma, desenvolvesse pelo menos os dois níveis inferiores da taxonomia.

Cientes que a principal vantagem da SAI são as atividades/interações presenciais desenvolvidas em sala de aula (Bishop \& Verleger, 2013;Van Alten et al., 2019) e que a sua qualidade depende, por um lado, do modo de atuação do professor, da sua capacidade de diferenciar as atividades de aprendizagem, de dar feedback e orientar, por outro lado, do tipo de atividades propostas que influenciam o modo como os alunos se envolvem nas tarefas que, por sua vez, afetam o nível de compreensão dos conteúdos com repercussões nos resultados alcançados (Van Alten et al., 2019). Seria, portanto, expectável que devido ao aumento do tempo e das oportunidades de interação com os pares e o professor, bem como de praticar e aplicar conhecimentos, se possibilitasse a aprendizagem colaborativa (DeLozier \& Rhodes, 2017) e se promovesse o desenvolvimento de dimensões cognitivas de ordem superior na taxonomia, o que se traduziria numa melhoria dos resultados escolares. 
Nesse sentido, fomos comparar a média dos resultados obtidos nos quizzes com a média dos resultados dos testes formativos. A aplicação do teste- $t$ permitiu aceitar a hipótese que a média dos quizzes foi inferior à média dos testes formativos, logo é provável que as interações desenvolvidas em aula tivessem permitido o desenvolvimento das dimensões cognitivas de ordem superior. No entanto, a incidência da aprendizagem colaborativa no desenvolvimento dessas dimensões aparenta ser muito residual, conforme se verifica no gráfico 1. Deduzimos, portanto, que as interações que fomentaram um maior envolvimento dos alunos com as atividades e permitiram o desenvolvimento de tais dimensões foram as estabelecidas com o professor, que através de uma atuação diferenciada, atendeu às necessidades dos alunos.

Será, então, necessário implementar dinâmicas que alavanquem a aprendizagem colaborativa, tal é a sua importância, pois apoiando-nos na perspetiva de Vygotsky (1978) a aquisição do conhecimento ocorre por mediação, convivência e partilha. Trazendo esse processo benefícios para todos, pois os "alunos que ajudam outros, enfrentam, também, desafios cognitivos, nomeadamente no que respeita à simplificação, clarificação e exemplificação" (Topping \& Ehly, 1998, p. 13).

Num estudo efetuado por Strayer (2012), que comparou os ambientes de aprendizagem desenvolvidos numa sala de aula tradicional e numa SAI, o autor concluiu que embora os alunos estivessem insatisfeitos com a SAI, a colaboração era fomentada neste ambiente em virtude da pouca estruturação e imprevisibilidade das atividades nele desenvolvidas. Os alunos aperceberam-se do valor da cooperação e da aprendizagem em grupo para conseguirem concluir as tarefas propostas e finalizar o curso.

No design da nossa proposta SAI, seguindo as recomendações do FNL, estruturamos e detalhamos os procedimentos de cada componente SAI, não só para facilitar a transição para este novo formato, mas também para minimizar a insatisfação com a proposta. Contudo, à medida que os alunos se familiarizem com a proposta será importante verificar se a diminuição do nível de estruturação das atividades incentiva a colaboração entre eles.

QI2: Se a implementação da proposta SAI provocou alterações no processo de aprendizagem, será que essas alterações estão alinhadas com os princípios do PAFC?

0 facto de os alunos receberem os materiais instrucionais, antes da AP, responsabilizou-os pela exploração desses materiais, de modo a se prepararem para as atividades a realizar na AP, o que ficou evidenciado pela elevada percentagem de envolvimento com a AO (96\% preparou sempre ou quase sempre a $\mathrm{AO}$ e o envolvimento foi a segunda categoria mais frequente no discurso dos alunos sobre a $\mathrm{AO}$ ). Ao serem disponibilizados vídeos didáticos, os alunos puderam controlar a sua aprendizagem, quer através do número de vezes que os visualizaram, quer através do ritmo, podendo pausar, repetir ou avançar (Ribeirinha \& Silva, 2020) permitindo uma preparação eficiente da AO (evidenciada pelos resultados dos quizzes).

Há categorias transversais nas duas componentes do modelo (figura 1) que, também, caracterizam a SAI (figura 2), são elas o envolvimento e a inovação. O envolvimento dos alunos já foi debatido na questão anterior, porém, a inovação é uma categoria emergente do discurso dos alunos. Não é de estranhar o aparecimento desta categoria, pois a implementação da SAI implicou uma rutura com o modelo de aprendizagem que os alunos estavam habituados. Passaram de uma utilização da tecnologia esporádica e passiva, 
caracterizada por "Apresentações digitais de conteúdos didáticos pelo professor/alunos" e "Comunicação com os alunos" (dados do Q1) para utilização diária e autónoma, quer no acesso online dos materiais didáticos divulgados pelo professor, quer no uso, em sala de aula, nas diversas simulações e quizzes. No entanto, esta passagem não é automática, a familiarização com o modelo requer tempo, e acarreta um trabalho extra que os alunos devem ter para uma preparação conveniente da AO (Wang, 2016). Daí que a categoria aspetos negativos surja com bastante frequência na análise do discurso da A0, estando relacionada com a sobrecarga de trabalho que esta preparação exige. Acrescendo o facto de alguns alunos terem uma ideia bastante convencional da aprendizagem (Wang, 2016), também evidenciada nesta turma pela elevada percentagem de preferência pela metodologia de aprendizagem "Explicação do professor" (95\%, Q1).

No sentido de minimizar a prevalência dos aspetos negativos destaca-se o papel do professor. 0 professor deve salientar que as tarefas de recuperação e ampliação dos conteúdos, que se fazem em sala de aula com a sua ajuda e dos colegas, requerem tempo curricular, daí a necessidade de fazerem o trabalho previsto para a AO. Este tipo de explicação dá significado ao trabalho da AO, que ao consolidar-se, cria agência e autonomia nos alunos e promove a mudança de hábitos de aprendizagem (Lo \& Hew, 2017).

A análise do discurso sobre a AP fez emergir mais categorias quando comparada com a AO, entre as quais, o apoio do professor e a satisfação com aula. Estas duas categorias intrinsecamente ligadas com as preferências dos alunos (Q1), destacam também a dimensão humana do professor, pois relacionam-se com os aspetos de ajuda, incentivo, interesse e preocupação do professor para com os seus alunos. Reconhecendo a afetividade como promotora do avanço e do desenvolvimento dos indivíduos (Wallon, 1975), o investimento na qualidade do relacionamento entre professor e aluno torna o processo educativo mais significativo para o aluno com repercussões na sua perceção de satisfação.

É sob esse olhar que se operacionalizam os princípios humanísticos do PAFC, centrando a educação na formação humana, sem nunca a reduzir a uma aprendizagem técnica (por mais especializada que seja), pois "transformar a experiência educativa em puro treinamento técnico é amesquinhar o que há de fundamentalmente humano no exercício educativo: o seu caráter formativo" (Freire, 2006, p. 33). Esse caráter formativo evidencia o respeito pela natureza do ser humano quando a aprendizagem conjuga também a formação cívica. Portanto, o processo de construção do conhecimento deve, também, fornecer ao aluno competências, através das quais possa estabelecer uma ligação significativa entre as dimensões cognitivas, afetivas sociais e éticas. São os aspetos de interação e respeito pelos outros que impulsionam as dinâmicas de grupo e, consequentemente, a aprendizagem colaborativa. No entanto, este processo é lento e gradual, daí que no imediato, tenha pouca incidência na análise do discurso dos alunos sobre a AP.

A implementação da SAI deu forma a alguns princípios orientadores do PAFC. Centrou a aprendizagem no aluno, responsabilizando-o pelo processo de aprendizagem e através de uma otimização do tempo pedagógicodidático, permitiu-lhes de forma ativa e participativa a construção de conhecimentos. No entanto, há aspetos que precisam de ser consolidados e melhorados para promover uma maior aceitação do modelo e desenvolver nos alunos competências de colaboração que vão de encontro à dimensão humanista do PAFC. 


\section{CONSIDERAÇÕES FINAIS}

No atual contexto de mudança da escola portuguesa, introduzido pelo PAFC, e sustentado na necessidade de práticas educativas mais inovadoras, assentes na colaboração, diferenciação e promotoras de uma educação escolar relevante, a I-A pareceu-nos a metodologia mais apta para investigar o potencial de uma proposta de aprendizagem híbrida. No entanto, dadas as características do estudo, surgiram certas limitações que de seguida elencamos. 0 tempo de implementação da proposta, foi curto, o que pode ter condicionado os resultados obtidos pelo efeito da novidade. Na comparação dos testes formativos com os quizzes, idealmente, cada quiz devia ser comparado com o respetivo teste formativo e, apesar de na sua conceção se atender aos mesmos princípios, devia ter sido garantida a homogeneidade desses instrumentos. Por último, a impossibilidade de generalização dos resultados, pois embora se tenham usado instrumentos variados que possibilitaram a triangulação dos dados obtidos, os resultados empíricos referem-se a um contexto de pesquisa muito particular.

Contudo, esta pesquisa possibilitou uma compreensão mais profunda e completa do fenómeno em estudo. A análise dos resultados permitiu concluir que as principais caraterísticas da proposta implementada são o envolvimento e a inovação. Esse envolvimento é evidente tanto para a componente online como presencial. $\mathrm{O}$ envolvimento dos alunos com a AO permitiu-lhes assumir o controlo da sua aprendizagem e prepará-la convenientemente, pois desenvolveram as duas dimensões cognitivas inferiores da taxonomia de Bloom revista. Contudo, a insatisfação com o trabalho da AO é algo que deve ser melhorado, através de uma comunicação mais assertiva que valorize a sua execução sistemática e permita a consolidação e o enraizamento de tais práticas.

A complementaridade entre as duas componentes do modelo proporcionou aos alunos uma experiência integrada de aprendizagem, suportada pelo modo de atuação do professor. A qualidade das interações em sala de aula permitiu que os alunos desenvolvessem e ampliassem os conteúdos estudados autonomamente e foi responsável pelo envolvimento ativo dos alunos na AP, o que levou ao desenvolvimento de dimensões cognitivas de ordem superior da taxonomia. No entanto, esse processo de construção do conhecimento não pôs em evidência as competências afetivas e sociais que são valorizadas nas dinâmicas de grupo e, consequentemente, na aprendizagem colaborativa.

No sentido de incrementar todo o potencial da aprendizagem híbrida e desenvolver nos alunos competências afetivas e sociais que vão de encontro à dimensão humanista do $\mathrm{PAFC}$, o professor parece-nos ser a peça chave. Ao assumir que as interações com e entre os alunos constituem o núcleo da sua ação pedagógica, o professor educa com o intuito de desenvolver e pôr em prática os valores por que se deve pautar a cultura da escola, enunciados no PA, contribuindo, assim, para a formação de pessoas mais humanas, solidárias e com atitudes mais democráticas.

\section{AGRADECIMENTOS}

Este trabalho é financiado pelo CIEd - Centro de Investigação em Educação, Instituto de Educação, Universidade do Minho, projetos UIDB/01661/2020 e UIDP/01661/2020, através de fundos nacionais da FCT/MCTES-PT. Também foi desenvolvido no âmbito do Programa de Doutoramento "Technology 
Enhanced Learning and Societal Challenges", financiado pela Fundação para a Ciência e Tecnologia, FCT I. P. - Portugal, contrato \# PD/BD/150424/2019.

\section{REFERÊNCIAS}

Bergmann, J., \& Sams, A. (2012). Flip your classroom: Reach every student in every class every day. International Society for Technology in Education. International Society for Technology in Education World.

Boelens, R., De Wever, B., \& Voet, M. (2017). Four key challenges to the design of blended learning: A systematic literature review. Educational Review Research, 22, 1-18. http://doi.org/10.1016/j.edurev.2017.06.001

Bishop, J. L., \& Verleger, M. A. (2013). The flipped classroom: A survey of the research. Proceedings of the 120th ASEE National Conference, 30, 1-18.

Coutinho, C. P., Sousa, A., Dias, A., Bessa, F., Ferreira, M. J. R. C., \& Vieira, S. R. (2009). Investigação-acção: Metodologia preferencial nas práticas educativas. Psicologia, Educação e Cultura, 13(2), 355-379.

DeLozier, S. J., \& Rhodes, M. G. (2017). Flipped classrooms: A review of key ideas and recommendations for practice. Educational Psychology Review, 29(1), 141-151. https://doi.org/10.1007/s10648-015-9356-9

Press.

Elliott, J. (1991). Action research for educational change. Open University

Fisher, J., Bushko, K., \& White, J. (2017). Blended beyond borders: A scan of blended learning obstacles and opportunities in Brazil, Malaysia \& South Africa.

Christensen Institute.

https://www.christenseninstitute.org/wpcontent/uploads/2017/11/BlendedBeyondB orders.pdf

Flipped Learning Network (2014). The four pillars of F-L-I-P. South Bend, Flipped Learning. http://www.flippedlearning.org/domain/46

Freire, P. (2006). Pedagogia da autonomia. Paz e Terra.

Gross, D., Pietri, E. S., Anderson, G., Moyano-Camihort, K., \& Graham, M. J. (2015). Increased preclass preparation underlies student outcome improvement in the flipped classroom. CBE-Life Sciences Education, 14(4), 1-8.

https://doi.org/10.1187/cbe.15-02-0040.

Horn, M. B., \& Staker, H. (2015). Blended: Using disruptive innovation to improve schools. Jossey-Bass.

Kemmis, S. (1993). La formación del profesor y la creación de comunidades críticas de profesores. Investigación en la Escuela, 19, 15-38.

Kemmis, S. (2007). Action research. In M. Hammersley (Ed.), Educational Research and Evidence-based Practice (pp. 167-180). Sage Publications.

Kirschner, P. A., Sweller, J., \& Clark, R. E. (2006). Why minimal guidance during instruction does not work. Educational Psychologist, 41(2), 75-86.

https://doi.org/10. 1207/s15326985ep4102_1

Krathwohl, D. R. (2002). A revision of Bloom's Taxonomy: An overview.

Theory Into Practice, 41(4), 212-218.

https://www.tandfonline.com/doi/abs/10.1207/s15430421tip4104_2

Lape, N. K., Levy, R., Yong, D. H., Haushalter, K. A., Eddy, R., \& Hankel, N. (2014). Probing the inverted classroom: A controlled study of teaching and learning outcomes in undergraduate engineering and mathematics. ASEE Annual Conference and Exposition, Conference Proceedings, USA, 121, 9475. https://www.asee.org/public/conferences/32/papers/9475/download.

Lo, C. K., \& Hew, K. F. (2017). A critical review of flipped classroom challenges in $\mathrm{K}-12$ education: Possible solutions and recommendations for future 
research. Research and Practice in Technology Enhanced Learning, 12(4), 1-22. https://doi.org/10.1186/s41039-016-0044-2

Mayer, R. (2001). Multimedia learning. Cambridge University Press.

McLaughlin, J. E., Griffin, L. M., Esserman, D. A., Davidson, C. A., Glatt, D. M., Roth, M. T., Gharkholonarehe, N., \& Mumper, R. J. (2013). Pharmacy student engagement, performance, and perception in a flipped satellite classroom. American Journal of Pharmaceutical Education, 77(9), 1-8. https://doi.org/10.5688/ajpe779196

Monteiro A., Moreira, J., \& Lencastre, J. (2015). Blended learning na sociedade digital. Wh!tebooks.

Morán, J. (2015). Mudando a educação com metodologias ativas. In A. C. Souza \& O. Morales (Orgs.), Coleção Mídias Contemporâneas. Convergências Midiáticas, Educação e Cidadania: Aproximações jovens (vol. II), (pp. 15-33). Foca FotoPROEX/UEPG. http://www2.eca.usp.br/moran/wpcontent/uploads/2013/12/mudando_moran.pdf Morin, E. (2003). Os sete saberes necessários à educação do futuro. Cortez Editora.

Ribeirinha, T., \& SILVA, B. (2020). Avaliando a eficácia da componente online da "Sala de Aula Invertida": Um estudo de Investigação-Ação. Revista ecurriculum, Dossiê Temático 2020: "Web Currículo: Educação e humanismo", 18(2), 568-589. https://doi.org/10.23925/1809-3876.2020v18i2p568-589

Rodrigues, S. V. (2018). Três modos de organizar sequências de aprendizagem interdisciplinares com base nas aprendizagens essenciais. http://www.dge.mec.pt/sites/default/files/boletim/aprendizagens_essenciais_consoli dacao-articulacao.pdf

Roldão, M. C., \& Almeida, S. (2018). Gestão curricular para a autonomia da escola e dos professores. Ministério da Educação, Direção Geral de Educação. http://www.dge.mec.pt/sites/default/files/Curriculo/AFC/Livro_gestao_curricular.pdf.

Silva, B., Pereira, A., \& Almeida, L. (2017). Innovation in B-learning: Feelings Experienced by the students of the master's in educational technology. In G. İın, S. İın, B. Silva, A. J. Osório \& J. Lencastre (Eds.), Better e-Learning for Innovation in Education (pp. 79-104). Çukurova University.

Strayer, J. F. (2012). How learning in an inverted classroom influences cooperation, innovation and task orientation. Learning Environment Research, 15, 171-193. https://doi.org/10.1007/s10984-012-9108-4

Sun, J. C. Y., Wu, Y. T., \& Lee, W. I. (2017). The effect of the flipped classroom approach to Open Course Ware instruction on students' self-regulation. British Journal of Educational Technology, 48(3), 713-729. http://dx.doi.org/10.1111/bjet.12444

Topping, K. J., \& Ehly, S. W. (1998). Introduction to peer-assisted learning. In K. J. Topping \& S. W. Ehly (Eds.), Peer-assisted learning (pp. 1-23). Lawrence Erlbaum Associates.

UNESCO-BIE. (2016). Glossário de terminologia curricular. http://www.ibe.unesco.org/sites/default/files/resources/ibe-glossarycurriculum_por.pdf

Van Alten, D.C.D., Phielix, C., Janssen, J., \& Kester L. (2019). Effects of flipping the classroom on learning outcomes and satisfaction: A meta-analysis. Educational Research Review, 28, 1-18. https://doi.org/10.1016/j.edurev.2019.05.003.

Vygotsky, L. S. (1978). Mind in society: The development of higher psychological processes. Harvard University Press.

Wallon, H. (1975). Psicologia e educação da infância. Estampa. 
Wang, Y. (2016). Could a mobile-assisted learning system support flipped classrooms for classical Chinese learning? Journal of Computer Assisted Learning, 32(5), 391-415. https://doi.org/10.1111/jcal.12141

WEF (2018). The Future of Jobs Report. Centre for the New Economy and Society. http://abet-trabalho.org.br/wpcontent/uploads/2018/12/WEF_Future_of_Jobs_2018.pdf.

\section{LEGISLAÇÃO CONSULTADA}

Despacho n 6478/2017, 26 de julho (2017). Direção Geral da Educação. https://www.dge.mec.pt/sites/default/files/Curriculo/Projeto_Autonomia_e_Flexibili dade/perfil_dos_alunos.pdf.

Despacho n. ${ }^{\circ}$ 5908/2017, de 5 de julho (2017). Direção Geral da Educação, Diário da República, $2 .^{a}$ série, n. $^{\circ} 128$ de 5 de julho de 2017, pp. 1388113890.

http://dge.mec.pt/sites/default/files/Curriculo/Projeto_Autonomia_e_Flexibilidade/d espacho_5908_2017.pdf.

Informação dos autores:

i CIEd-IE Universidade do Minho, Portugal. https: //orcid.org/0000-0002-5678-3476

ii CIEd-IE Universidade do Minho, Portugal. https: //orcid.org/0000-0001-5394-5620

Toda a correspondência relativa a este artigo deve ser enviada para:

Teresa Ribeirinha

Rua da Boavista, n. ${ }^{\circ} 158$, Candoso S. Martinho.

4835-368 Guimarães

teresaribeirinha@hotmail.com

Recebido em 1 de novembro de 2020

Aceite para publicação em 16 de abril de 2021 
The coexistence between online and face-to-face learning in the students' training process: An action-research study on the operationalization of the Flipped Classroom in Portuguese secondary education

\begin{abstract}
The "Projeto de Autonomia e Flexibilidade Curricular" (PAFC) challenges the work dynamics of schools, through regulations that advocate innovative practices promoting differentiated learning and transversal skills. Blended learning is identified as the key to the renewal of school practices, as it enables more dynamic and personalized learning. This text evaluates a blended learning educational proposal the "flipped classroom", designed to operationalize the PAFC principles. An actionresearch cycle, developed in a secondary school class, allowed to collect quantitative and qualitative data to evaluate this operationalization and to understand the impact of the proposal on school results and students' perceptions. The results analysis highlights in the proposal the innovation, the student's engagement, and the complementarity between the online and face-to-face classes, which provided an integrated learning experience supported by the teacher. Classroom interactions allowed students to extend the contents studied autonomously and to develop cognitive dimensions of a higher order. However, the knowledge construction process did not highlight the social skills valued in group dynamics and collaborative learning advocated in the PAFC.
\end{abstract}

Keywords: "Projeto de Autonomia e Flexibilidade Curricular"; Blended learning; Flipped classroom 
La coexistencia entre el aprendizaje en línea y presencial en el proceso de formación de los estudiantes: Un estudio de investigación-acción sobre la operacionalización del "Aula invertida" en la educación secundaria portuguesa

\section{RESUMEN}

El "Projeto de Autonomia e Flexibilidade Curricular" (PAFC) desafía la dinámica de trabajo de las escuelas, a través de reglamentos que abogan por prácticas innovadoras que promueven el aprendizaje diferenciado y las competencias transversales. Se señala que el aprendizaje híbrido es la clave para renovar las prácticas escolares, ya que permite un aprendizaje más dinámico y personalizado. Este texto evalúa una propuesta educativa de aprendizaje híbrido, el "aula invertida", diseñada para poner en práctica los principios del PAFC. En este sentido, un ciclo de investigación-acción, desarrollado en una clase de la escuela secundaria, permitió reunir datos cuantitativos y cualitativos para evaluar esta operacionalización y comprender el impacto de la propuesta en los resultados y las percepciones de los estudiantes. El análisis de los resultados pone de relieve en la propuesta la innovación, la participación de los estudiantes y la complementariedad entre las clases en línea y las clases presenciales, que proporcionaron una experiencia de aprendizaje integrada con el apoyo del profesor. Las interacciones en el aula permitieron a los estudiantes ampliar los contenidos estudiados de forma autónoma y desarrollar dimensiones cognitivas de orden superior. Sin embargo, el proceso de construcción de conocimientos no ha puesto de relieve las aptitudes sociales valoradas en la dinámica de grupo y el aprendizaje en colaboración que se propugnan en el PAFC.

Palabras-clave: "Projeto de Autonomia e Flexibilidade Curricular"; Aprendizaje híbrido; Aula invertida 